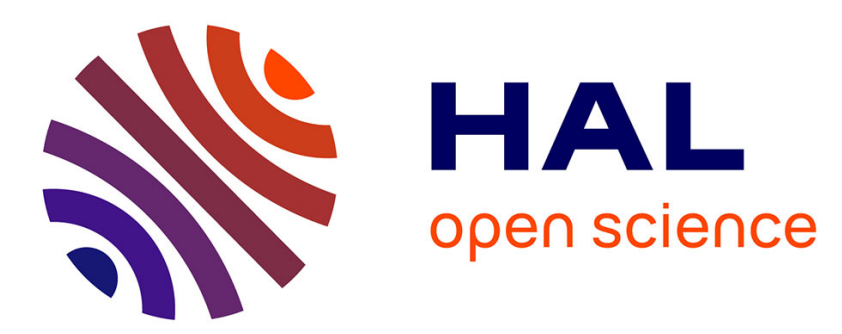

\title{
As time goes by: space-time compatibility effects in word recognition
}

Camille Grasso, Johannes C Ziegler, Jonathan Mirault, Jennifer T Coull, Marie Montant

\section{- To cite this version:}

Camille Grasso, Johannes C Ziegler, Jonathan Mirault, Jennifer T Coull, Marie Montant. As time goes by: space-time compatibility effects in word recognition. Journal of Experimental Psychology: Learning, Memory, and Cognition, 2021, 10.1037/xlm0001007 . hal-03193618

\section{HAL Id: hal-03193618 \\ https://hal-amu.archives-ouvertes.fr/hal-03193618}

Submitted on 7 Oct 2021

HAL is a multi-disciplinary open access archive for the deposit and dissemination of scientific research documents, whether they are published or not. The documents may come from teaching and research institutions in France or abroad, or from public or private research centers.
L'archive ouverte pluridisciplinaire HAL, est destinée au dépôt et à la diffusion de documents scientifiques de niveau recherche, publiés ou non, émanant des établissements d'enseignement et de recherche français ou étrangers, des laboratoires publics ou privés. 


\section{As time goes by: space-time compatibility effects in word recognition}

Camille L. Grasso ${ }^{1}$, Johannes C. Ziegler ${ }^{1}$, Jonathan Mirault ${ }^{1}$, Jennifer T. Coull ${ }^{2}$, \& Marie Montant ${ }^{1}$ 1Aix-Marseille Université, CNRS, Laboratoire de Psychologie Cognitive (UMR 7290)

${ }^{2}$ Aix-Marseille Université, CNRS, Laboratoire de Neurosciences Cognitive (UMR 7291)

\section{Author Note}

Camille L. Grasso (iD) https://orcid.org/0000-0002-7549-7395

Email: Camille.grasso@univ-amu.fr

We have no known conflict of interest to disclose. 


\begin{abstract}
The processing of time activates a spatial left-to-right mental timeline, where past events are "located" to the left and future events to the right. If past and future words activate this mental timeline, then the processing of such words should interfere with hand movements that go in the opposite direction. To test this hypothesis, we conducted three visual lexical decision tasks with conjugated (past/future) verbs and pseudo-verbs. In Experiment 1, participants moved a pen to the right or left of a trackpad to indicate whether a visual stimulus was a real word or not. Grammatical time and hand movements for yes responses went in the same direction in the congruent condition (e.g., past tense/leftward movement) but in opposite directions in the incongruent condition. Analyses showed that space-time incongruency significantly increased reaction times. In Experiment 2, we investigated the role of movement in this effect. Participants performed the same task by responding with a trackpad or a mouse, both of which required lateral movement through space, or a static key-press. We again obtained the space-time congruency effect, but only when the decision required movement through space. In Experiments 1 and 2, stimuli were preceded by a temporal prime. In Experiment 3, participants performed the same task without any prime. Results replicated the congruency effect, demonstrating that it does not depend upon temporal word priming. Altogether, results suggest automatic activation of a left-right mental timeline during word recognition, reinforcing the claim that the concept of time is grounded in movement through space.
\end{abstract}

Keywords: Word recognition, embodied cognition, time, space. 


\section{As time goes by: space-time compatibility effects in word recognition}

How do we understand and represent the meaning of words? Over the past decades, one of the most influential views comes from the field of embodied cognition (Anderson, 2010; Barsalou, 2008; Manzotti, 2019; Pulvermüller, 1999, 2018). According to this view, there are no abstract linguistic representations of meaning but rather meaning is "grounded" in bodily interactions and sensorimotor experiences (Barsalou, 2008; Borghi et al., 2017; Kiefer \& Barsalou, 2013; Pulvermüller, 2005; Pulvermüller \& Fadiga, 2010). It has been suggested that word meaning is represented in widely distributed cell assemblies that associate the core language network with networks in charge of processing sensorimotor, motor and emotional information across modalities (Garagnani \& Pulvermüller, 2016; Pulvermüller \& Fadiga, 2010;). For example, action verbs, such as kick, pick and lick, activate the corresponding action systems (Pulvermüller, 2005), odor-related words, such as cinnamon, activate the primary olfactory cortex (González et al., 2006), taste-related words, such as salt, activate primary and secondary gustatory cortices (Barrós-Loscertales et al., 2012), and disgust words, such as vomit, activate the anterior insula (Ziegler et al., 2018). It has also been shown that these areas are activated early enough ( $\sim 200 \mathrm{~ms}$ after word onset $)$ to participate in the very construction of meaning (Ponz et al., 2014; Pulvermüller et al., 2005).

The idea that meaning is grounded in bodily interactions and sensorimotor experiences has not gone uncriticized. For instance, it has been argued that many of the results are simply neurophysiological correlates rather than causal evidence, and that some results are at variance with strong neurophysiological claims about grounded cognition (Miller et al. 2018). One of the main arguments against embodied theories of cognition and language is that these theories cannot explain how abstract concepts and words are processed and represented (Mahon \& Caramazza, 2008). How can we understand abstract words, such as quantum physics, for which we have no sensorimotor experience? In the present article, we investigated this issue for a special category of abstract words, namely those that implicitly carry information about time. Indeed, time is a universal but highly abstract concept. We can feel time but we cannot touch it. We can measure time but we cannot interact with it. In fact, there is no specific organ dedicated to the perception of time (Grondin, 2001). So, how can words that refer to time be grounded in bodily sensorimotor experience? 
Recent lines of research suggest that time representations are intimately linked to spatial representations. One key idea is that time is spatially organized, running along a left-right and front-back axis, which results in what is referred to as a mental timeline (for reviews see Bonato et al., 2012; Eikmeier et al., 2015). Two prominent theories have been proposed to explain the close relationship between time and space. On the one hand, the Theory of Magnitude (ATOM, Walsh, 2003) suggests that every action requires the systematic and simultaneous processing of time and space, which results in a common neuronal network for the processing of space, time and other magnitudes (e.g., number). As a consequence, consistent with the idea that space and time share common networks, the model predicts that time processing might interfere with spatially lateralized sensorimotor responses (Bueti \& Walsh, 2009). On the other hand, the Conceptual Metaphor Theory (CMT, Lakoff, 1987; Lakoff \& Johnson, 1980,1999) suggests that people use spatial metaphors to speak about time (e.g., a "long" versus "short" time). The theory argues that we conceptualize and understand the abstract concept of time by mapping it onto the more concrete and experience-based domain of space (Boroditsky, 2000; Lakoff \& Johnson, 1999). Thus, both theories argue for a close link between time and space and also highlight the role of sensorimotor experience (for reviews, see Bender \& Beller, 2014; Núñez \& Cooperrider, 2013; Winter et al., 2015).

Previous results suggest that abstract words referring to time might be grounded in sensorimotor processes. For example, Santiago and colleagues (2007) asked participants to categorize past- and future-related words that were presented either to the right or to left of fixation by pressing a response button with either the left or right hand. They found that participants were faster when past words appeared on the left side of the screen or were responded to with their left hand, and when future words appeared on the right side of the screen or were responded to with their right hand, suggesting that the abstract dimension of time leads to the activation of concrete spatial associations. In another study, Kong and You (2012) tested this space-time congruency effect in two auditory tasks and found that time-related words primed motor responses and oriented attention to left or right space. Ouellet and colleagues (2010) found similar results when participants had to keep time-related words in working memory while detecting stimuli presented to the left or right side of a screen (Exp. 1), or during a spatial Stroop task (Exp. 2). Finally, it has been reported that brain- 
damaged patients with hemispatial neglect who ignore the left side of space also have difficulties representing past events (Anelli et al., 2018; Saj et al., 2014), which supports the claim that space plays a functional role in the conceptualization of time.

The space-time congruency effect was also found when participants processed entire sentences referring to past or future events. In a first experiment, Ulrich and Maienborn (2010) asked participants to decide whether visually presented sentences referred to the past or the future. They found that participants were faster when the future sentence required a right-hand response and the past sentence a left-hand response, rather than the other way around (for other evidence see Eikmeier et al., 2015; Maienborn et al., 2015; Walker et al., 2014). However, they failed to replicate these results in follow-up experiments when the temporal information conveyed by the sentence (past/future) was no longer relevant for the task (Maienborn et al., 2015; Ulrich \& Maienborn, 2010). In contrast, Sell and Kaschak (2011) found a significant space-time congruency effect for temporal sentences during a sensibility judgment task (i.e., decide whether the sentence makes sense or not), in which temporal information was task-irrelevant. In their study, short three-sentence stories referring to past or future events were presented, and participants had to make a sensibility judgment in one of two ways: (1) pressing an "upper" or "lower" response button on a keyboard by moving the index finger of their right hand upwards (away from their body) or downwards (toward their body) or (2) pressing the toward or away buttons with the left and right index finger without moving. They found a space-time congruency effect only for the movement condition, suggesting that temporal information automatically activates the mental timeline. These results were recently replicated by Scheifele and colleagues (2018). Two main experimental differences could explain the differences in the results of Ulrich and Maienborn (2010) and Sell and Kaschak (2011): the direction of the mental timeline and the type of responses. Indeed, in Ulrich and Maienborn (2010), participants were tested on the left-right axis and responded by pressing a key without any directed movement while in Sell and Kaschak, participants were tested on the front-back axis and responded by moving their arm along that axis.

This question of which conditions give rise to space-time congruency effects was recently addressed in a comprehensive meta-analysis by von Sobbe et al. (2019), which included space-time congruency effects obtained in 30 published studies (62 effect size measures). The authors distinguished three types of experiments: (1) experiments 
where time was task-relevant, (2) experiments where time was task-irrelevant, and (3) experiments using time-related primes. They estimated the size of the 62 space-time congruency effects using Cohen's d, that is the difference in mean RTs between congruent and incongruent conditions. They observed that the size of the effects was much bigger when time was task-relevant $(d=0.46)$ or when time-related primes were used $(d=0.47)$ than when time was task-irrelevant $(\mathrm{d}=0.09)$. This led the authors to conclude that the mental timeline is more likely activated when temporal reasoning is required for the task.

The present experiments were designed to test whether robust space-time congruency effects can be obtained when time is task-irrelevant. However, instead of judging whether sentences made sense, as in Sell and Kaschak (2011), we chose a simple lexical decision task of single words that referred to future or past actions. That is, participants were asked to make a "yes"/"no" decision as to whether conjugated (past/future) verbs were real words as opposed to pseudowords. The grammatical verbal system in French makes it possible to use the same word stem combined with a suffix that indicates either past tense (je marchais [I walked]; je rêvais [I dreamt]) or future tense (je marcherai [I will walk]; je rêverai; [I will dream]). Having the same word stem for different temporal conditions nicely controls for possible orthographic, lexical and semantic confounds. In Experiment 1, participants made their "yes"/"no" decisions by moving their right arm towards the left or the right side of a trackpad that recorded response accuracy and reaction times. For the congruent condition, verb tense and hand movements went in the same direction (e.g., past tense associated with a leftward movement; future tense associated with a rightward movement). For the incongruent condition, verb tense and hand movements went in opposite directions. That is, when the "yes" response required a leftward movement responses were incongruent with future-tense words whereas when the "yes" decision required a rightward movement they were incongruent with past-tense words (see Figure 1 for an illustration of the design). We expected that an incongruent mapping of space-time should interfere with the execution of motor responses (i.e., longer reaction times) and lexical decision performance (i.e., higher error rates). In our view, obtaining a space-time congruency effect in a simple lexical decision task, for which the number of processing stages is limited (Plaut, 1997) and the processing of time is not explicitly required, would provide strong evidence for automatic grounding of language in sensorimotor experience. 


\section{Experiment 1}

\section{Methods}

Participants

We recruited 45 participants at Aix-Marseille University (Marseille, France). Six participants were not included in the analyses (due to software errors or participants who withdrew from the experiment). The remaining 39 participants were all French native speakers (22 women), right-handed (controlled by mean laterality quotient, Edinburgh Handedness inventory; Oldfield, 1971), reported normal or corrected-to-normal vision and no neurological or psychiatric disorders. They were between 18 and 38 years old $(M=24.5 ; S D=2.6)$ and signed informed-consent forms prior to participation in accordance with the provisions of the Word Medical Association Declaration of Helsinki.

Design and Stimuli

We selected 160 verbs in the infinitive form from Lexique3 database (New et al., 2005). Half of them were used to create the word stimuli and the other half to create the pseudowords. Pseudowords were generated by changing one letter from their baseword (e.g., vomber from tomber in French / palk from walk in English; see Appendix A). Words and pseudowords or their basewords were matched with respect to length ( 7.23 versus 7.30 letters, $p=.49$ for words versus pseudowords, respectively), frequency ( 80.89 versus 72.54 occurrences per million, $p=.17$, for words versus pseudowords, respectively), uniqueness point (5.29 versus 5.33, $p=0.74$, for words versus pseudowords, respectively) and syllable number (2.40 versus $2.48, p=.40$, for words versus pseudowords, respectively). Participants saw each word only once. Because each word could appear in past- or future-tense and to the right or to the left (see Figure 1), we created four counter-balanced lists of 160 stimuli each ( 80 words, 80 pseudowords) using a Latin-Square design. Half of the stimuli in each list were in the past tense, preceded by the pronoun "I" (e.g., I walked / I palked), half were in the future (e.g., I will walk/ I will palk). 
Apparatus

Stimuli were displayed on a 15 -inch LCD screen in black 37-point monospaced fonts (droid sans mono) on a grey background. The experiment was created using OpenSesame (Version 3.2.6; Mathôt et al., 2012). Participants used their right (dominant) hand to move a pen to the right or to the left of a trackpad for the "yes"/"no" decision (Genius EasyPen 340). The left and right response areas of the trackpad were spatially delimited by a virtual boundary $(+/-700$ pixels from the centre on the trackpad, for the left and right responses, respectively). Yes- and no-responses to the left and right side on the trackpad were counterbalanced across conditions and participants, that is, during half of the experiment, participants were instructed to move the pen towards one side of the trackpad for real words ("yes" responses) and to the opposite side for pseudowords ("no" response) and, after a short pause, the word/pseudoword responses sides were reversed. To restrict movement only to the wrist and reduce movement variability across trials and participants, participants placed their right hand on a wrist rest.

\section{Procedure}

The experiment was run in a quiet testing room. Participants completed the Edinburgh Handedness Inventory (Olfdfield, 1971) and received instructions in written and oral form. They were instructed to decide as rapidly and as accurately as possible whether the stimulus was a French word or not by moving the pen towards the left or right side of the trackpad (see Figure 2). Half of the participants started with "yes" responses towards the left of the trackpad, half of the participants started with "yes" responses towards the right. The direction of response was reversed during the second part of the experiment for all participants. Participants were trained before the beginning of the experiment, as well as halfway through. They started the experiment after reaching a threshold of $80 \%$ correct responses during training (approximately 30 trials). Each participant saw a total of 80 words and 80 pseudowords randomized in two counterbalanced blocks ("yes" to the right and "yes" to the left). When the "yes" response was to the right, futuretense words were congruent and past-tense words were incongruent (see Figure 1). In this block, 20 words were futurecongruent and 20 words were past-incongruent (i.e., total of 40 words per block, 20 words per condition). When the "yes" response was to the left, past-tense words were congruent and future-tense words were incongruent. In this block, 
we had 20 past-congruent and 20 future-incongruent words (i.e., total of 40 words per block, 20 words per condition).

This design allowed us to present each stimulus in the past or future tense, during the first or the second part of the experiment, and in congruent or incongruent conditions.

The experiment started once the training session was completed. As can be seen in Figure 2, at the beginning of each trial, a fixation cross was displayed in the centre of the screen for a duration that varied randomly between 200 and $300 \mathrm{~ms}$, followed by a prime for $500 \mathrm{~ms}$, a blank display for $400 \mathrm{~ms}$ and then the target (e.g., I walked). In order to reinforce the salience of temporal information, each target was preceded by a congruent prime, that is, all past-tense words and pseudowords were primed by "Yesterday" and all future-tense words and pseudowords were primed by "Tomorrow". Targets stayed on the screen until the response of the participant, that is until the pen crossed the virtual boundary of the response area. Therefore, response times corresponded to the time needed to reach the boundary after the onset of the target. After the response, participants were required to replace the pen at the centre (represented by a black dot) before each new trial. The pen had to be at the centre to start a new trial. If the participants responded too slowly, a beep was played after 1000ms (post target onset). In between the blocks (after 80 trials), participants had a 2-minute break, and they were instructed to change the response direction for "yes"/"no" decisions. They started a new training phase before completing the second part of the experiment.

Analyses

The data were analyzed using both standard analyses of variance (ANOVA) with either participants $(F 1)$ or items $(F 2)$ as the random variables and linear mixed effect models with participants and items as crossed random effects (Baayen, et al., 2008; Barr et al., 2013). For the ANOVAs, we used a $2 \times 2$ within-participant ANOVA with Side and Time as factors. Note that the congruency effect is the interaction between Side and Time. That is, when the side of the response for a past-tense word (e.g., he walked) changes from left to right, the word stops being congruent and, instead, becomes incongruent. Similarly, when the side of the response for a future-tense word (e.g., he will walk) changes from left to right, the word stops being incongruent and becomes congruent (see Figure 1). 
For the linear mixed-effect analyses, latency data were fitted with lmer and accuracy data with glmer functions from the lme4 package (Bates et al., 2015) in the R statistical computing environment (Version 3.5.2; R Core Team, 2018). We report unstandardized regression coefficients, standard errors (SEs), and t values (for lmer) or z values (for glmer). Fixed effects were deemed reliable if $|t|$ or $|z|$ was greater than 1.96 (Baayen, 2008). We used the maximal random structure model that reached convergence (Barr et al., 2013), and this included by-participant and by-item random intercepts in all analyses that we report. Fixed effects, random effects, and random slopes were only included if they significantly improved the model's fit in a forward stepwise model selection procedure. Models were selected using chi-squared log-likelihood ratio tests with regular maximum likelihood parameter estimation. Following the procedure described by Brysbaert and Stevens (2018), we conducted power analysis based on 1000 simulations with powerSim functions from the simR package (Green \& MacLeod, 2016; Green et al., 2016).

\section{Results}

We analyzed the reaction time (RTs) of correct responses and error rates (ER) for 39 participants. Statistical analyses were conducted separately for words and pseudowords. We first removed extreme values (i.e., RTs below $250 \mathrm{~ms}$ or above $4000 \mathrm{~ms}$ ), then we considered as outliers data points that were above or below 2.5 standard deviations from each individual participant's mean RT. Outliers were replaced by the cut-off RT corresponding to each participant's mean +/- 2.5 standard deviation (see Hoaglin et al., 1986).

Words

The results for the word trials are shown in Figure 3. We conducted a $2 \times 2$ within-participant ANOVA, which resulted from the factorial combination of the effects of Side (left versus right) and Time (past vs. future).

As concerns RTs, the ANOVA showed no significant main effect of Time, $F 1(1,38)=.49, p>.49$ and $F 2$ $(1,79)=2.16, p>.14$, or Side, $F 1(1,38)=2.44, p>.12$ and $F 2(1,79)=2.77, p>.10$, but a highly significant interaction between the effects of Time and Side, $F 1(1,38)=12.59, p<.001$ and $F 2(1,79)=12.232, p<.001$. As explained above, the significant interaction reflects the congruency effect. That is, when the side of the response for a 
past-tense word (I walked) changes from left to right, the word becomes spatially inconsistent (i.e., incongruent). By contrast, when the side of the response for a future-tense word (I will walk) changes from left to right, the word becomes spatially consistent (i.e., congruent). The interaction results from the fact that congruent words were generally responded to more quickly than incongruent words.

In the mixed effect analyses of RT data, the final model included Time, Side, Block and the interaction between Time and Side as fixed effects. As random effects, we had by-participant and by-item intercepts, random slopes for side, and random slopes for time by-participants. The results showed a significant effect of Time $(b=37.927$, $S E=9.48, t=4.00)$, Side $(b=35.717, S E=14.27, t=2.50)$, and a significant interaction between Time and Side $(b=$ $-52.181, S E=10.79, t=4.84)$. There was also an effect of Block $(b=-21.410, S E=11.34, t=1.89)$, which reflected the fact that participants were faster in the second block but this effect did not interact with the effects of interest. Contrast analyses showed that participants were faster to respond for congruent than for incongruent words $(b=-$ 36.034, $\mathrm{SE}=14.81, \mathrm{t}=2.43)$, and this congruency effect did not interact with Time $(b=20.336, \mathrm{SE}=27.62, \mathrm{t}=0.74)$. The power of this last model (i.e., congruency and time) in 1000 simulated studies was .78, $\mathrm{CI}_{95}=[76.24,81.39]$.

As concerns response accuracy (ERs), the ANOVA showed a significant main effect of Time (past vs. future), $F 1(1,38)=9.13, p<.01$ and $F 2(1,79)=11.44, p<.001$, reflecting the fact that past-tense words yielded higher error rates than future-tense words. The main effect of Side (left v. right) was not significant, $F 1(1,38)=.18, p>.50$ and $F 2(1,79)=.71, p>.40$. The critical interaction between the effects of Time and Side (congruency effect) failed to reach significance, $F 1(1,38)=2.24, p>.15$ and $F 2(1,79)=3.41, p=.069$.

In the mixed effect analyses of accuracy data, the final model included Time, Side and their interaction as fixed effects. As random effects, we had random intercepts for participants and items. As in the ANOVA analyses, there was a significant effect of Time $(b=-0.852, S E=0.22, z=3.91)$ and a marginally significant interaction between Side and Time $(b=0.570, S E=0.30, z=1.88)$. Contrast analysis of this interaction showed that participants made more errors in the incongruent condition than in the congruent condition $(b=0.516, S E=0.22, z=2.31)$. No other effects were significant. The power of this last model (i.e., congruency and time) in 1000 simulated studies was .67, $\mathrm{CI}_{95}=[64.09,70.01]$. 


\section{Pseudowords}

Responses to three pseudowords where excluded from the analyses because of high error rates (between $38 \%$ and $89 \%)$.

As concerns RTs, the ANOVA showed no significant effects of Side $\left(F_{\mathrm{S}}<1\right)$, Time $(F 1(1,38)=2.09, p>$ .15 and $F 2(1,76)=1.49, p>.20)$ and no significant interaction between the effects of Side and Time $\left(F_{\mathbf{s}}<1\right)$. The final linear mixed model for the RT data included Side, Time and their interaction, as well as block (Part1 vs Part2). As random effects, we had by-participants and by-items random intercepts, and by-participants random slopes for the effect of tense and side. Participants were faster during the second block of the experiment $(b=-32.620, S E=10.00$, $t=3.26)$. No other significant effects were obtained.

As concerns accuracy data, the ANOVA revealed a significant effect of Time $F 1(1,38)=5.63, p<.05$ and $F 2(1,76)=2.35, p>.14$, but no effect of Side $(F \mathrm{~s}<1)$ and no significant interaction between the effects of Time and Side $F 1(1,38)=2.18, p>.14$ and $F 2(1,76)=1.16, p>.25$. The final linear mixed effect model of the accuracy data included Side, Time and their interaction. As random effects, we had intercepts for subjects and items, as well as byitems random slopes for the effect of tense. A marginally significant effect of Time was obtained reflecting the fact participants made more errors for past-tense than future-tense pseudowords ( $b=0.436, S E=0.23, z=1.89$ ). No other effect was significant.

\section{Discussion}

In line with our prediction, we found a significant space-time congruency effect in visual word recognition. Lexical decision movements that were incongruent with the mental timeline resulted in an increase in reaction times and to some extent error rates. That is, participants were slower when they had to move to the right for words that referred to past events and to the left for words that referred to future events. Although the effects went in the same direction for error rate (more errors for incongruent words), the critical time by space interaction failed to reach significance. However, the absence of a significant effect on errors is not necessarily a problem. In response-limited conditions (i.e., when stimuli are unmasked, presentation time is unlimited and performance is typically high), the 
critical dependent variable is latency not error rate (Grainger \& Jacobs, 1996). Indeed, in the lexical decision task, most psycholinguistic effects in skilled adult readers show up on latencies rather than error rates (Coltheart et al., 2001). Not surprisingly, the dominant models of the lexical decision task are concerned with explaining response time distributions rather than errors (Dufau et al., 2012; Ratcliff et al., 2004).

Our results join those of Sell and Kaschak (2011) to suggest that the processing of temporal information in the language domain automatically activates the mental timeline, which interferes with movement through space. The fact that the congruency effect was only found for words but not for pseudowords suggests that this effect was generated by time-relevant information stored in lexical representations and not by sub-lexical processes.

An important issue remains to be addressed. Several studies have failed to find a space-time congruency effect along the left-right axis when temporal information was not relevant to the task (Maienborn et al., 2015; Ulrich \& Maienborn, 2010; Ulrich and Maienborn, 2010; von Sobbe et al., 2019), leading these authors to conclude that the mental timeline is not automatically activated during semantic processing of concepts related to time and, instead, reflects facilitated memory access rather than automatic sensorimotor activation (Maienborn et al., 2015; von Sobbe et al., 2019). One of the key differences between studies that found space-time congruency effects and those that failed to find these effects is the involvement of movement. Indeed, Maienborn and colleagues (Ulrich and Maienborn, 2010; Maienborn et al., 2015) used static and lateralized hand responses (e.g., a button press with the right hand to indicate the future and a button press with the left hand to indicate the past), whereas Sell and Kaschak (2011) found a congruency effect only for an arm movement condition but not for a static button-press condition (for a replication, see also Scheifele et al., 2018). This suggests that movement might be the key component underlying the spatial organization of the mental timeline and its functional role during semantic processes of grammatical time (past/future). Experiment 2 was designed to replicate our results and further investigate the importance of movement for the occurrence of space-time congruency effects in word recognition. 


\section{Experiment 2}

Experiment 2 was designed to replicate the results found in Experiment 1 and to directly assess the role of movement in the space-time congruency effect. To this end, the same space-time manipulation was used, but participants had to respond either with a trackpad or mouse, both of which required lateral movement through space, or a lateralized key-press, which didn't. If spatially directed movement were the key component of the space-time compatibility effect, we would expect a space-time compatibility effect only in the movement conditions.

In addition, we tested whether rendering the temporal information more salient by using a prime is a necessary condition to obtain significant space-time compatibility effects. In Experiment 1, a prime (Yesterday/Tomorrow) was systematically and consistently associated with the subsequent verb, which reinforced the temporal context and created a minimal syntactic structure (Tomorrow I will walk) that might have amplified the effects. Thus, in Experiment 2, we decided to systematically manipulate the presence of a prime in half of the trials.

To increase the power of the experiment, and as a consequence of the 2020 coronavirus-related lockdown in France, we opted for an on-line experiment that yielded data from more than 1100 students from Aix-Marseille University.

\section{Methods}

\section{Participants}

A total 1104 students from Aix-Marseille University participated in our on-line experiment. The experiment was advertised through a mailing list to all university students. Students were free to participate and data collection was totally anonymous. To motivate a large number of students to participate in the experiment, they were informed that a number of participants (1:50) were randomly drawn to receive a monetary reward of 50 euros for their participation.

Because the data from on-line experiments are much noisier than laboratory experiments, we first cleaned the data, which resulted in the exclusion of 44 participants who had incomplete data or gave aberrant responses: 26 participants did not report the type of device they used for responding (i.e., trackpad or mouse), 7 participants had 
error rates above $75 \%$ suggesting they had inverted response mappings, and 11 participants repeatedly answered using the same response side. We then removed aberrant RTs (see the results section for more details) and calculated the mean RT and 2.5 standard deviations from the mean for all participants. We then excluded 42 participants whose mean RTs were more than 2.5 standard deviations above or below the mean of the group. Overall, this exclusion procedure left us with the data from 1018 participants that were included in the final analysis. In order to simplify the procedure and instructions for this on-line experiment, in Experiment 2 we did not ask participants to change the side of yesresponses halfway through the experiment. Therefore, for half of the participants, the yes-response was always on the left side, and for the other half, the yes-response was always on the right side.

The participants were on average 23 years-old ( $S D=5.3$, ranging from 17 to 64 years old), 642 were female, 887 were right-handed, 110 were left-handed and 21 were ambidextrous. 294 participants did the experiment using a trackpad (150 responded "yes" to the right and 144 responded "yes" to the left), 208 participants used a mouse (118 left yes-responses and 90 right yes-responses), and 516 participants did the experiment using a keyboard (251 left yesresponses and 265 right yes-responses). Stimuli and Apparatus

The stimuli were identical to those of Experiment 1. The experiment was programmed using PHP, JAVASCRIPT and HTML. Participants were asked to either use the keyboard, mouse or trackpad. For the keyboard, participants gave their response by pressing the ' $Q$ ' key for left answers and ' $M$ ' for right answers (azerty keyboard) with their left and right index fingers. For the mouse or trackpad, participants moved their mouse or their finger on the trackpad toward to the left- or right side of space using their dominant hand. A virtual boundary was placed $10 \%$ to the left and $10 \%$ to the right of both edges in order to detect "yes" and "no" responses.

\section{Design and Procedure}

The design was almost identical to that of Experiment 1 with four notable exceptions. First, participants were asked to respond either with a mouse or trackpad (movement) or with a keyboard (no movement). Second, the side of the response was fixed for a given participant to avoid participants having to change response sides halfway through the experiment. Third, half of the trials were preceded by a congruent prime word, (i.e., "Yesterday" for past tense 
stimuli and "Tomorrow" for future tense stimuli) and the other half were preceded by a black square (no priming). Fourth, a 400ms feedback stimulus was added to the end of the trial (i.e., a green cross for correct responses or a red cross for incorrect responses) to maintain participants' motivation and a beep was played $1500 \mathrm{~ms}$ after target onset to discourage slow responses.

When opening the web link of the online experiment, each participant was assigned at random to either a movement condition (trackpad our mouse) or a no-movement condition (keyboard) and to a response side ("yes" responses to the left or "yes" responses to the right). Participants were instructed to decide as rapidly and as accurately as possible whether the stimulus was a French word or not. The sides to which "yes" responses were made were counterbalanced across participants. Participants were asked to perform the experiment in a quiet environment with no acoustic and visual distractions. They started the experiment after completing a questionnaire (i.e., age, gender, education level, dominant hand and device used) and a short training of 20 trials.

Analyses

The procedure for data analyses was identical to that of Experiment 1.

\section{Results}

We analyzed RTs for correct responses and response accuracy (ERs) for 1018 participants. After visual inspection of the RT distributions, we first removed extreme RTs that were below $300 \mathrm{~ms}$ and above $3000 \mathrm{~ms}$ for the trackpad, below $250 \mathrm{~ms}$ and above $3000 \mathrm{~ms}$ for the mouse and below $250 \mathrm{~ms}$ and above $2500 \mathrm{~ms}$ for the keyboard. Then, we identified outliers that were beyond 2.5 standard deviations from the individual mean RT and we winsorized these data points (Hoaglin et al., 1986). The average RTs and error rates for each condition are shown in Figure 4. Statistical analyses were conducted separately for words and pseudowords. 
Words

Two sets of ANOVAs were conducted with subjects $(F 1)$ and items $(F 2)$ as random variables. In the $F 1$ analyses, Device (Trackpad, Mouse, Keyboard) and Side (left versus right) were between-subject factors and Time (past vs. future) and Prime (with, without) were within-subject factors. In the $F 2$ analyses, all factors were within-item because every word stem had been seen in every condition.

The ANOVA analysis of RT data showed significant main effects of Device $[F 1(2,1012)=243.88, p<.001$; $F 2(2,158)=5436.91, p<.001]$, Side $[F 1(1,1012)=15.38, p<.001 ; F 2(1,79)=368.14, p<.001]$ and Prime $[F 1(1$, $1012)=80.71, p<.001 ; F 2(1,79)=56.53, p<.001]$. Time was not significant $(\mathrm{F} s<1)$. Importantly, the congruency effect, which is the interaction between Time and Side, was highly significant $[F 1(1,1012)=30.18, p<.001 ; F 2(1$, 79) $=17.23, p<.001]$. Moreover, the triple interaction between Time, Side and Device was significant by participants but not by items $[F 1(2,1012)=3.02, p<.05 ; F 2(1,79)=1.78, p>.15]$, which indicates that the congruency effect was modulated by Device. Indeed, when we combined the two movement conditions (trackpad and mouse) and contrasted them with the no-movement condition (keyboard), the triple interaction between Time, Side and Movement was significant by participants and by items $[F 1(2,1014)=6.57, p<.05 ; F 2(1,79)=4.17, p<05]$, which indicated that the congruency was larger in the movement conditions than in the no-movement condition (see more detailed analyses below). Prime did not affect the congruency effect, that is the triple interaction between Time, Side and Device was not significant $(F \mathrm{~s}<1)$. Prime only interacted significantly with Device $[F 1(2,1012)=7.72, p<.001$; $F 2(2,158)=3.87, p<.05]$, reflecting the fact that the priming effects were larger for devices that produced longer RTs (mouse and trackpad).

As concerns the mixed effect analysis of the RT data, the final model included Time (past vs future), Side (left vs right), Device (i.e., trackpad, mouse or keyboard), Prime (i.e., with or without) and their interaction, byparticipant and by-item random intercepts, and a random slope for prime by-participants. Results showed a significant effect of Time $(b=23.482, S E=5.10, t=4.60)$, Side $(b=50.576, S E=13.866, t=3.65)$, Device $(b=-84.666, S E=$ 6.57, $t=12.89)$, and Prime $(b=-30.516, S E=7.09, t=4.30)$. Moreover, results revealed that device interact significantly with Time $(b=-13.573, S E=3.7, t=4.03)$ and with Prime $(b=-9.539, S E=3.49, t=2.73)$. Importantly, 
as in the ANOVA analyses, the critical interaction between Side and Time (i.e., the congruency effect) was significant $(b=-30.516, S E=7.09, t=4.30)$ and this congruency effect was modulated by Device, as seen in a three-way interaction between Side, Time and Device $(b=12.016, S E=4.75, t=2.53)$. No other effect was significant. Given that this three-way interaction was significant, we conducted separate analyses for each condition (i.e., trackpad, mouse and keyboard).

Trackpad. The final model included Time (past vs future), Congruency (congruent vs congruent), Prime (i.e., with and without) and their interaction, by-participant and by-item random intercepts, and random slopes for tense byparticipants and by-items. Results showed significant effects of Congruency $(b=-40.573, S E=17.65, t=2.30)$ and Prime $(b=25.462, S E=6.26, t=4.07)$. Importantly, the prime effect did not interact with congruency effect $(b=$ $0.850, S E=8.94, t=0.09)$. The power of this model in 1000 simulated studies was .89, CI95=[87.22, 91.15]. No other effect was significant.

Mouse. The final model included Time (past vs future), Congruency (congruent vs congruent), Prime (i.e., with and without) and their interaction, by-participants and by-items random intercepts, and random slopes for tense by-participants and by-items. Results showed significant effects of Time $(b=-64.882, S E=19.91, t=3.26)$, Congruency $(b=-66.632, S E=20.27, t=3.29)$ and Prime $(b=14.581, S E=6.45, t=2.26)$. As for trackpad experiment, the prime effect did not interact with the congruency effect $(b=3.87, S E=9.89, t=0.52)$ or with Time $(b=-5.123$, $S E=9.83, t=0.39)$. Moreover, the congruency effect significantly interacted with Time $(b=111.931, S E=37.93, t=$ 2.95). The power of this model in 1000 simulated studies was $.90, \mathrm{CI} 95=[88.40,92.15]$. More precisely, participants were faster to respond when tense was congruent with side of response for left-side responses (i.e., past-congruent and future-incongruent condition ; $b=-17.96, S E=4.83, t=3.78$ ) but not for right-side responses (i.e., past-incongruent and future-congruent condition ; $b=3.154, S E=4.27, t=0.74)$.

Keyboard. The final model included Time (past vs future), Congruency (congruent vs congruent), Prime (i.e., with and without) and their interaction, by-participant and by-item random intercepts, and random slopes for tense byparticipant and by-item. Results showed significant effects of prime $(b=9.55, S E=3.48, t=2.75)$. No other effect was significant. 
The ANOVA analysis of the accuracy data showed significant main effects of Device $[F 1(2,1012)=22.00$, $p<.001 ; F 2(2,158)=40.94, p<.001]$ and Time $[F 1(1,1012)=39.90, p<.001 ; F 2(1,79)=7.771, p<.001]$ but no significant effect was obtained for Prime $[F 1(1,1012)=1.80, p>.15 ; F 2(1,79)=1.670, p>.20]$. Side was significant by items but not by participants $[F 1(1,1012)=3.08, p>.05 ; F 2(1,79)=8.63, p<.001]$. Importantly, the congruency effect, which is the interaction between Time and Side, was highly significant $[F 1(1,1012)=15.54, p<.001 ; F 2(1$, 79) $=26.94, p<.001]$. No other interaction was significant $\left(\right.$ all $\left.F_{S}<1\right)$.

The final mixed effect model of the accuracy data included Time (past vs future), Side (left vs right) and Device (i.e., trackpad, mouse or keyboard) and their interaction, as well as Prime (i.e., with or without) as a covariate fixed effect, by-participant and by-item random intercepts, and a random slope for tense by-participants. Participants made more errors for past-tense than future-tense words $(b=-0.648, S E=0.22, z=2.95)$. In addition, a significant effect of Device was observed $(b=-0.328, S E=0.06, z=5.39)$ and this effect interacted with Time $(b=0.157, S E=$ $0.06, z=2.46)$. As in the ANOVA analysis, the critical interaction between Side and Time (i.e., the congruency effect) was significant $(b=0.513, S E=0.14, z=3.52)$. No other effect was significant.

\section{Pseudowords}

The data from two pseudowords were excluded from the analyses because of high error rates (i.e., $46.89 \%$ and $79.84 \%)$.

The ANOVA of the RT data showed significant main effects of Device $[F 1(2,1012)=255.56, p<.001$; $F 2(2,154)=4727.22, p<.001]$, Side $[F 1(1,1012)=9.52, p<.01 ; F 2(1,77)=175.231, p<.001]$ and Time $[F 1(2$, $1012)=27.120, p<.001 ; F 2(1,77)=4.22, p<.05]$. Prime failed to reach significance $[F 1(1,1012)=2.98, p<.10$ $F 2(1,77)=1.137, p>.20]$. None of the interactions were significant (all $\left.F_{\mathrm{s}}<1.72\right)$.

As concerns the mixed effect analysis of RT data, the final model included Time (past vs future), Side (left vs right), Device (i.e., trackpad, mouse or keyboard) and their interaction, as well as Prime (i.e., with or without) as a covariate effect, by-participant and by-item random intercepts, and by-participant random slopes for tense. Results showed a significant effect of Time $(b=-10.982, S E=3.70, t=2.97)$, Device $(b=-104.981, S E=6.84, t=15.35)$ and a marginally significant effect of Side $(b=26.825, S E=14.39, t=1.86)$. No other effect was significant. 
The ANOVA of the accuracy data showed a significant main effect of Device $[F 1(2,1012)=18.85, p<.001$; $F 2(2,154)=69.887, p<.001]$ and Time $[F 1(2,1012)=6.27, p<.001 ; F 2<1]$. No other effects or interactions were significant (all $\left.F_{\mathrm{S}}<1.45\right)$.

The final mixed effect model of the accuracy data included Time (past vs future), Side (left vs right), Device (i.e., trackpad, mouse or keyboard), prime (i.e., with or without) and their interaction. As random effects, we had byparticipant and by-item random intercepts, and by-item random slopes for tense. Results showed a significant effect of Device $(b=-0.149, S E=0.07, z=2.09)$, a marginally significant effect of Prime $(b=0.211, S E=0.12, z=1.80)$, and a marginally significant interaction between them $(b=-0.142 ., S E=0.07, z=1.93)$. No other effect was significant.

\section{Discussion}

The goal of Experiment 2 was to test whether movement through space is the key component for the occurrence of the space-time congruency effect in word recognition and whether the presence of a prime was necessary for this effect to occur. The results are clear-cut. A significant space-time congruency effect on RTs was only observed when participants had to produce a directed movement through space. In these conditions, movements that were incongruent with the mental timeline resulted in a RT increase. No congruency effect on RTs was found when participants simply pressed a key on a keyboard (i.e., no movement condition). Note, however, that overall response speed in the keyboard condition was faster, which leaves open the possibility that there was less room to observe timespace congruency effects in the keyboard condition simply because responses were faster. This issue would need to be addressed in future experiments, that match overall response speed across conditions. In the accuracy data, we found a robust congruency effect in all conditions. As already discussed, we believe that in the standard lexical decision paradigm (response-limited as opposed to data-limited conditions), the theoretically important dependent variable is latency rather than error rate (Grainger \& Jacobs, 1996). Altogether, Experiment 2 perfectly replicated the main results of Experiment 1 in a much larger sample and with two independent movement conditions. Experiment 2 also highlights the fact that large-scale on-line experiments can usefully supplement standard laboratory experiments and substantially increase the power of the experiment. 
As concerns the effect of priming (i.e., presentation of "yesterday"/"tomorrow" before the target), we found that the presence of the prime had an overall effect on latencies (i.e., participants were faster in the prime condition than the no-prime condition) but the prime effect did not interact with the congruency effect or any other effect of interest. This result suggests that the presence of a prime was not necessary for the congruency effect to be observed. However, in Experiment 2, the presence of a prime was manipulated within-participants (i.e., a prime was present or not on half of the trials). Thus, one could still argue ${ }^{1}$ that the prime, which was present on half of the trials, increased the salience of the temporal dimension generally throughout the experiment, resulting in an artificially magnified congruency effect.

\section{Experiment 3}

Experiment 3 was identical to the trackpad condition of Experiment 2, except that no prime was presented before the stimuli. If the space-time congruency effects found in Experiments 1 and 2 were elicited or amplified by the presentation of temporal word primes, we should observe smaller or no congruency effect in the absence of priming.

\section{Methods}

\section{Participants}

A total of 52 students from Aix-Marseille University participated in an on-line experiment. The experiment was advertised through a mailing list of university students. Students were free to participate and data collection was totally anonymous. To recruit a large number of participants, students received course credits for their participation.

Because the data of on-line experiments are noisier than the data of laboratory experiments, we first cleaned them, which resulted in the exclusion of 4 participants who gave aberrant responses: 2 participants had error rates above $95 \%$, which suggests that they inverted response mappings, and 2 participants repeatedly answered using the

\footnotetext{
${ }^{1}$ We thank an anonymous reviewer for making this suggestion
} 
same response side. We then removed aberrant RTs (see the results section for more details) and we calculated the mean reaction time and 2.5 standard deviations from the mean for all participants. As in Experiment 2, we did not ask participants to change the side with which they made yes-responses halfway through the experiment. Therefore, for half of the participants, the yes-response was always on the left side, and for the other half, the yes-response was always on the right side.

The participants were on average 22 years-old $(S D=4.5$, ranging from 17 to 44 years old), 42 were female, 41 were right-handed, 7 were left-handed. As concerns response side, 25 participants responded "yes" to the right side and 23 responded "yes" to the left side.

Stimuli and Procedure

We used the same stimuli as in Experiment 1 and 2. Experiment 3 was identical to Experiment 2, except that no prime was presented before the stimuli.

Analyses

The procedure for data analyses was identical to that of Experiment 1 and 2.

\section{Results}

We analyzed reaction times (RTs) for correct responses and error rates (ER) for 48 participants. Statistical analyses were conducted separately for words and pseudowords. As in Experiments 1 and 2, we first removed extreme values (i.e., RTs below $250 \mathrm{~ms}$ or above $3000 \mathrm{~ms}$ ), then we considered as outliers data points that were above or below 2.5 standard deviations from each individual participant's mean RT. Outliers were replaced by the cut-off RT corresponding to each participant's mean +/- 2.5 standard deviation (see Hoaglin et al., 1986). 
Words

The results for the word trials are shown in Figure 5. We conducted a $2 \times 2$ within-participant ANOVA, which resulted from the factorial combination of the effects of Side (left versus right) and Time (past vs. future).

As concerns RTs, the ANOVA showed no significant main effect of Time, $F 1(1,46)=0.49, p>.50$ and $F 2$ $(1,79)=0.53, p>.50$. The main effect of Side was significant by items only, $F 1(1,46)=0.43, p>.05$ and $F 2(1,79)=$ $4.83, p<.05$. Critically, the interaction between the effects of Time and Side, which reflects the time-space congruency effect, was significant, $F 1(1,46)=4.57, p<.05$ and $F 2(1,79)=5.21, p<.05$.

In the mixed effect analyses of RT data, the final model included Time, Side and the interaction between Time and Side as fixed effects. As random effects, we had by-participant and by-item intercepts, and by-item random slopes for side. The results showed no effect of Time $(b=16.25, S E=11.45, t=1.42)$ or Side $(b=54.48, S E=50.13$, $t=1.09)$, but a significant interaction between Time and Side $(b=-42.05, S E=16.51, t=2.55)$. The power of this last model (i.e., Side and time) in 1000 simulated studies was .70, $\mathrm{CI}_{95}=[67.46,73.22]$.

Accuracy analyses showed no significant effects in the ANOVA (all $F \mathrm{~s}<1$ ). The mixed effect analyses of the accuracy data revealed a significant effect of Side $(b=-0.643, S E=0.29, z=2.21)$ but no other effect was significant.

Pseudowords

The $2 * 2$ ANOVA with Side and Time as factors showed no significant main effects of Side or Time and no significant interaction (all $F_{\mathrm{S}}<1$ ). The mixed effects analyses showed no significant effect.

\section{Discussion}

Experiment 3 was designed to rule out the hypothesis that the presentation of a temporal prime prior to the target words might have artificially produced a congruency effect by increasing the temporal salience of the stimuli and/or the task setting. To this end, we replicated the movement condition of Experiment 2, but in the absence of a temporal prime. According to von Sobbe et al.'s classification (2019), this corresponds to an experimental situation in which time is task-irrelevant. As in Experiments 1 and 2, the results of Experiment 3 clearly showed a space-time 
congruency effect on latencies. These results suggest that the primes used in experiments 1 et 2 were not at the origin of the space-time congruency effect, and provide strong evidence in support of the hypothesis that the left-right mental time-line can be automatically activated in a time-irrelevant task.

\section{General Discussion}

Three experiments were designed to investigate whether the processing of isolated words that carry information about time (i.e., verb tense) would automatically activate spatial and motor networks and consequently affect both word processing and action execution along the left-right axis. To this end, participants performed a lexical decision task on conjugated (past/future) verbs and pseudoverbs by either moving their arm to the left or the right, or by pressing the left or right key of a keyboard. Importantly, the processing of grammatical time was not explicitly required to perform the task and was totally irrelevant for making correct lexical decisions. If words that carry grammatical information about time automatically activate the left/right mental timeline, we expected to observe a detrimental effect for incongruent space-time mappings (i.e., past on the right, future on the left) on both reaction times and error rates. Our results confirm these predictions and further show that directed movement through space was a necessary condition for the occurrence of a congruency effect on response latencies. Our results suggest that previous studies might have failed to find a congruency effect (e.g., Maienborn et al., 2015; Ulrich \& Maienborn, 2011) because they used static responses, such as key-presses. The three experiments of the present study converge to suggest that movement might be the key component underlying the activation of the mental timeline during semantic processes of grammatical time (past/future).

An interesting question is why words that carry information about time are associated with movement along a left-to-right mental timeline? One possibility might be related to our reading and writing system. Indeed, several behavioral studies have shown that the spatial organization of the mental timeline follows the direction of the reading and writing systems. For example, Fuhrman and Boroditsky (2010) showed that English speakers (who read and write from left to right) organized temporal events from left to right whereas Hebrew speakers (who read and write from right to left) showed the opposite pattern. This was also observed for Mandarin speakers who read and organize time 
vertically, with past events above and future events below (Boroditsky et al., 2011). Interestingly, a few minutes of mirror reading are sufficient to reverse the direction of the mental timeline (Casasanto \& Bottini, 2014). According to the authors, this demonstrates the causal role of the directionality of our writing system in the spatial mapping of time along a mental timeline. They concluded that the mental timeline follows writing direction because "progress through time corresponds to change in position along a linear spatial path" (Casasanto \& Bottini, 2014, p. 6). It is possible that the direction of the mental timeline emerges from this accumulation of motor experience, with earlier events being "located" to the left and later events to the right. This implies that the very representation of a time word (like futureand past-tense verbs) might include the motor execution component of left-to-right movements. Said differently, time words might be spatially embodied as their processing recruits neural networks necessary for motor execution. This would explain why movement seems to constitute a key factor in the automatic activation of the mental timeline.

More generally, the central role of movement in the conceptualization of time is supported by numerous theorical and empirical arguments. For example, in six experiments, Boroditsky and Ramscar (2002) noted that asking participants to imagine time moving towards them or, alternatively, themselves moving forward in time induced a change in their perspective about past and future events. These results imply that the mental timeline involves not only notions of spatial location but also movement through space. Moreover, this relation between motor action and the mental timeline is reflected by spontaneous gestures during speech. Analyses of participants' movements when they are talking about past or future events showed that speakers produced movements directed to the left for past events and to the right for future events (Casasanto \& Jasmin, 2012). Indeed, ATOM theory emphasizes that time and space share common mechanisms and brain networks with the motor system because spatial and temporal features are processed simultaneously for every action. Sell and Kaschak (2010) suggested that the observed space-time congruency effect was the result of activation of intraparietal and parietal regions implicated in the understanding of space, time, quantity and other magnitudes. Interestingly, the same regions are also involved in motor planning. According to the authors, "the mechanisms that are responsible for preparing and executing bodily action play a role in grounding the comprehension of language about abstract situation" (Sell \& Kaschak, 2011, p. 4). To our view, movement might be the bodily and physical experience that brings together space and time. 
One last issue that should be discussed concerns the automatic activation of the mental timeline and the necessary experimental conditions for a space-time congruency effect to be observed. As discussed in the Introduction, this issue has recently been addressed by von Sobbe et al. (2019) in a meta-analysis of the results of 30 published studies, in which they observed that the size of the time-space congruency effect was larger in experiments for which time was relevant $(d=0.46)$ or that included temporal priming, $(d=0.47)$ than for experiments in which time was task-irrelevant $(d=0.09)$. This led the authors to conclude that the mental timeline is more likely activated when temporal reasoning is required in the task. For the sake of comparison, we calculated Cohen's $d$ for the space-time congruency effects we observed in Experiments 1 to 3. These results are shown in Figure 6. We obtained values ranging from 0.38 to 0.74 (mean 0.45 ) when the participants answered using movement devices (trackpad and mouse) and 0.15 when participants answered using the keyboard. Note that in all of our experiments time was task-irrelevant (classic lexical decision) and the space-time congruency effect was observed in the absence of temporal priming (Exp 3). Thus, our experiments clearly fall into von Sobbe et al.'s "time is task-irrelevant" category, yet our effect sizes are closer to those obtained for experiments in their "time is relevant" or "temporal priming" categories. One explanation for this has already been discussed (i.e., the importance of movement). The other might have to do with the complexity of the tasks and stimuli used in previous studies. Indeed, in many previous studies, the authors used high-level tasks (sensibility judgments) and more complex stimuli (whole sentences or even stories). If the time-space congruency effect is rather low-level (early and automatic activation of a mental time-line that interferes with basic word recognition processes), one might expect that such effects are more difficult to bring out in more complex or higherlevel tasks. Finally, von Sobbe et al. made the distinction between low and high temporal complexity of the task and argued that the activation of the mental timeline (characterized by a significant congruency effect) occurs only when the level of temporal complexity was high. However, this cannot explain why we find comparable effect sizes in our own "time is task-irrelevant" experiments to those of von Sobbe et al.'s "time-is-relevant" experiments because the temporal complexity of our stimuli was rather low. 
To conclude, our results are relevant to a more general debate about how abstract concepts can be embodied. Indeed, according to the embodied view of language, meaning is supported by sensorimotor, introspective and emotional networks (Barsalou, 1999; Glenberg et al., 2013) with abstract concepts being "grounded" like concrete concepts, through experiential interactions during the acquisition of a concept or a meaning. For example, the emotional content of words selectively activates the corresponding primary emotion networks rapidly and automatically (Ponz et al., 2014; Ziegler et al., 2018). Similarly, processing motor and visual abstract words elicits activation in the respective motor and visual brain regions (Harpaintner et al., 2020). As suggested by Barsalou (2018, p.9), "because concepts emerge from processing situations, they are best studied in the context of situations", in which case the dissociation between concrete and abstract concepts appear no longer relevant. In our study, as suggested previously, we most likely found a space-time congruency effect during a non-temporal language task because we studied the abstract concept of time in its situational context, that of movement. 


\section{References}

Anderson, M. L. (2010). Neural reuse: A fundamental organizational principle of the brain. Behavioral and Brain Sciences, 33(4), 245-266.

Anelli, F., Avanzi, S., Arzy, S., Mancuso, M., \& Frassinetti, F. (2018). Effects of spatial attention on mental time travel in patients with neglect. Cortex, 101, 192-205.

Baayen, R. H. (2008). Analyzing linguistic data: A practical introduction to statistics using R. Cambridge, England: Cambridge University Press.

Baayen, R. H., Davidson, D. J., \& Bates, D. M. (2008). Mixed-effects modeling with crossed random effects for subjects and items. Journal of Memory and Language, 59(4), 390-412.

Barr, D. J., Levy, R., Scheepers, C., \& Tily, H. J. (2013). Random effects structure for confirmatory hypothesis testing: Keep it maximal. Journal of Memory and Language, 68(3), 255-278.

Barrós-Loscertales, A., González, J., Pulvermüller, F., Ventura-Campos, N., Bustamante, J. C., Costumero, V., ... \& Ávila, C. (2012). Reading salt activates gustatory brain regions: fMRI evidence for semantic grounding in a novel sensory modality. Cerebral Cortex, 22(11), 2554-2563.

Barsalou, L. W. (1999). Perceptual symbol systems. Behavioral and Brain Sciences, 22(4), 577-660.

Barsalou, L. W. (2008). Grounded cognition. Annual Review of Psychology, 59, 617-645.

Barsalou, L. W., Dutriaux, L., \& Scheepers, C. (2018). Moving beyond the distinction between concrete and abstract concepts. Philosophical Transactions of the Royal Society B: Biological Sciences, 373(1752), 20170144.

Bates, D., Mächler, M., Bolker, B., \& Walker, S. (2015). Fitting linear mixed-effects models using lme4. Journal of Statistical Software, 67. doi:10.18637/jss.v067.i01

Bender, A., \& Beller, S. (2014). Mapping spatial frames of reference onto time: A review of theoretical accounts and empirical findings. Cognition, 132(3), 342-382.

Bonato, M., Zorzi, M., \& Umiltà, C. (2012). When time is space: evidence for a mental time line. Neuroscience \& Biobehavioral Reviews, 36(10), 2257-2273. 
Borghi, A. M., Binkofski, F., Castelfranchi, C., Cimatti, F., Scorolli, C., \& Tummolini, L. (2017). The challenge of abstract concepts. Psychological Bulletin, 143(3), 263-292.

Boroditsky, L. (2000). Metaphoric structuring: Understanding time through spatial metaphors. Cognition, $75(1), 1-28$.

Boroditsky, L., Fuhrman, O., \& McCormick, K. (2011). Do English and Mandarin speakers think about time differently?. Cognition, 118(1), 123-129.

Boroditsky, L., \& Ramscar, M. (2002). The roles of body and mind in abstract thought. Psychological Science, 13(2), 185-189.

Brysbaert, M., \& Stevens, M. (2018). Power analysis and effect size in mixed effects models: A tutorial. Journal of Cognition, 1(1), 1-20.

Bueti, D., \& Walsh, V. (2009). The parietal cortex and the representation of time, space, number and other magnitudes. Philosophical Transactions of the Royal Society B: Biological Sciences, 364(1525), 1831-1840.

Casasanto, D., \& Bottini, R. (2014). Mirror reading can reverse the flow of time. Journal of Experimental Psychology: General, 143(2), 473-479.

Casasanto, D., \& Jasmin, K. (2012). The hands of time: Temporal gestures in English speakers. Cognitive Linguistics, 23, 643-674.

Coltheart, M., Rastle, K., Perry, C., Langdon, R., \& Ziegler, J. (2001). DRC: a dual route cascaded model of visual word recognition and reading aloud. Psychological Review, 108(1), 204-256.

Dufau, S., Grainger, J., \& Ziegler, J. C. (2012). How to say “no” to a nonword: A leaky competing accumulator model of lexical decision. Journal of Experimental Psychology: Learning, Memory, and Cognition, 38(4), 1117-28.

Eikmeier, V., Alex-Ruf, S., Maienborn, C., \& Ulrich, R. (2015). How strongly linked are mental time and space along the left-right axis?. Journal of Experimental Psychology: Learning, Memory, and Cognition, 41(6), 1878-1883.

Garagnani, M., \& Pulvermüller, F. (2016). Conceptual grounding of language in action and perception: a neurocomputational model of the emergence of category specificity and semantic hubs. European Journal of Neuroscience, 43(6), 721-737. 
Glenberg, A. M., Witt, J. K., \& Metcalfe, J. (2013). From the revolution to embodiment: 25 years of cognitive psychology. Perspectives on Psychological Science, 8(5), 573-585.

González, J., Barros-Loscertales, A., Pulvermüller, F., Meseguer, V., Sanjuán, A., Belloch, V., \& Ávila, C. (2006). Reading cinnamon activates olfactory brain regions. Neuroimage, 32(2), 906-912.

Grainger, J., \& Jacobs, A. M. (1996). Orthographic processing in visual word recognition: A multiple read-out model. Psychological Review, 103(3), 518-565.

Green, P., \& MacLeod, C. J. (2016). SIMR: an R package for power analysis of generalized linear mixed models by simulation. Methods in Ecology and Evolution, 7(4), 493-498.

Green, P., MacLeod, C. J., \& Alday, P. (2016). Package 'simr'.

Grondin, S. (2001). From physical time to the first and second moments of psychological time. Psychological Bulletin, 127(1), 22-44.

Fuhrman, O., \& Boroditsky, L. (2010). Cross-cultural differences in mental representations of time: Evidence from an implicit nonlinguistic task. Cognitive Science, 34(8), 1430-1451.

Harpaintner, M., Sim, E. J., Trumpp, N. M., Ulrich, M., \& Kiefer, M. (2020). The grounding of abstract concepts in the motor and visual system: An fMRI study. Cortex, 124(1), 1-22.

Hoaglin, D. C., Iglewicz, B., \& Tukey, J.W. (1986). Performance of Some Resistant Rules for Outlier Labeling. Journal of the American Statistical Association, 81(396), 991-999.

Kiefer, M., \& Barsalou, L. W. (2013). Grounding the human conceptual system in perception, action, and internal states. In W. Prinz, M. Beisert, \& A. Herwig (Eds.), Action science: Foundations of an emerging discipline (pp. 381-407). Cambridge: MIT Press.

Kong, F., \& You, X. (2012). Space-time compatibility effects in the auditory modality. Experimental Psychology, 59, 82-87.

Lakoff, G. (1987). Women, Fire and Dangerous Things. What Categories Reveal about the Mind. Chicago: University of Chicago. 
Lakoff, G., \& Johnson, M. (1980). Metaphors we live by. Chicago, IL: University of Chicago.

Lakoff, G., \& Johnson, M. (1999). Philosophy in the Flesh (Vol. 4). New York: Basic books.

Mahon, B. Z., \& Caramazza, A. (2008). A critical look at the embodied cognition hypothesis and a new proposal for grounding conceptual content. Journal of Physiology-Paris, 102(1-3), 59-70.

Maienborn, C., Alex-Ruf, S., Eikmeier, V., \& Ulrich, R. (2015). Do we map remembrances to the left/back and expectations to the right/front of a mental timeline? Space-time congruency effects with retrospective and prospective verbs. Acta Psychologica, 156(1), 168-178.Manzotti, R. (2019). Embodied AI beyond Embodied Cognition and Enactivism. Philosophies, 4(3), 39.

Mathôt, S., Schreij, D., \& Theeuwes, J. (2012). OpenSesame: An open-source, graphical experiment builder for the social sciences. Behavior Research Methods, 44(2), 314-324.

Miller, J., Brookie, K., Wales, S., Wallace, S., \& Kaup, B. (2018). Embodied cognition: Is activation of the motor cortex essential for understanding action verbs?. Journal of Experimental Psychology: Learning, Memory, and Cognition, 44(3), 335.

New, B., Pallier, C., \& Ferrand, L. (2005). Manuel de Lexique 3. Behavior Research Methods, Instruments, \& Computers, 36(3), 516-524.

Núñez, R., \& Cooperrider, K. (2013). The tangle of space and time in human cognition. Trends in cognitive sciences, $17(5), 220-229$.

Oldfield, R. C. (1971). The assessment and analysis of handedness: the Edinburgh inventory. Neuropsychologia, 9(1), 97-113.

Ouellet, M., Santiago, J., Israeli, Z., \& Gabay, S. (2010). Is the future the right time?. Experimental Psychology, $57(1), 308-314$

Plaut, D. (1997). Structure and function in the lexical system: Insights from Distributed Models of Word Reading and Lexical Decision. Language and Cognitive Processes, 12(5/6), 1-19. 
Ponz, A., Montant, M., Liegeois-Chauvel, C., Silva, C., Braun, M., Jacobs, A. M., \& Ziegler, J. C. (2014). Emotion processing in words: a test of the neural re-use hypothesis using surface and intracranial EEG. Social Cognitive and Affective Neuroscience, 9(5), 619-627.

Pulvermüller, F. (1999). Words in the brain's language. Behavioral and Brain Sciences, 22(2), 253-279.

Pulvermüller, F. (2005). Brain mechanisms linking language and action. Nature Reviews Neuroscience, 6(7), 576-582.

Pulvermüller, F., \& Fadiga, L. (2010). Active perception: sensorimotor circuits as a cortical basis for language. Nature Reviews Neuroscience, 11(5), 351-360.

Pulvermüller, F. (2018). The case of CAUSE: neurobiological mechanisms for grounding an abstract concept. Philosophical Transactions of the Royal Society B: Biological Sciences, 373(1752), 20170129.

Ratcliff, R., Gomez, P., \& McKoon, G. (2004). A diffusion model account of the lexical decision task. Psychological Review, 111(1), 159-182.

Saj, A., Fuhrman, O., Vuilleumier, P., \& Boroditsky, L. (2014). Patients with left spatial neglect also neglect the "left side" of time. Psychological Science, 25(1), 207-214.

Santiago, J., Lupáñez, J., Pérez, E., \& Funes, M. J. (2007). Time (also) flies from left to right. Psychonomic Bulletin \& Review, 14(3), 512-516.

Scheifele, E., Eikmeier, V., Alex-Ruf, S., Maienborn, C., \& Ulrich, R. (2018). A Replication of "Processing time shifts affects the execution of motor responses (Sell \& Kaschak, 2011; Experiment 1)”. The Quantiative Methods for Psychology, 14(1), 8-11.

Sell, A. J., \& Kaschak, M. P. (2011). Processing time shifts affects the execution of motor responses. Brain and Language, 117(1), 39-44.

Ulrich, R., \& Maienborn, C. (2010). Left-right coding of past and future in language: The mental timeline during sentence processing. Cognition, 117(2), 126-138.

von Sobbe, L., Scheifele, E., Maienborn, C., \& Ulrich, R. (2019). The Space-Time Congruency Effect: A Meta-Analysis. Cognitive Science, 43(1), e12709. 
Walker, E. J., Bergen, B. K., \& Núñez, R. (2014). Disentangling spatial metaphors for time using non-spatial responses and auditory stimuli. Metaphor and Symbol, 29(4), 316-327.

Walsh, V. (2003). A theory of magnitude: common cortical metrics of time, space and quantity. Trends in Cognitive Sciences, 7(11), 483-488.

Winter, B., Marghetis, T., \& Matlock, T. (2015). Of magnitudes and metaphors: Explaining cognitive interactions between space, time, and number. Cortex, 64, 209-224.

Ziegler, J. C., Montant, M., Briesemeister, B. B., Brink, T. T., Wicker, B., Ponz, A., ... \& Braun, M. (2018). Do words stink? Neural reuse as a principle for understanding emotions in reading. Journal of Cognitive Neuroscience, 30(7), 1023-1032. 


\section{Acknowledgments}

Camille Grasso was supported by a doctoral fellowship of the French Ministry of Higher Education, Research, and Innovation. This study benefited from support of the Institute of Convergence ILCB (ANR-16-

CONV-0002) and the Excellence Initiative of Aix-Marseille University A*MIDEX (ANR-11-IDEX-0001-02). 
Appendix A: Words and Pseudowords used in Experiment 1, 2 and 3.

\begin{tabular}{|c|c|c|c|c|c|c|}
\hline Base-word & Past tense & Future tense & Base-Word & Pseudowords & Past tense & Future tense \\
\hline pousser & je poussais & je pousserai & travailler & trapailler & je trapaillais & je trapaillerai \\
\hline laisser & je laissais & je laisserai & profiter & plofiter & je plofitais & je plofiterai \\
\hline permettre & je permettais & je permettrai & inquiéter & insuiéter & j'insuiétais & j'insuiéterai \\
\hline emmener & j'emmenais & j'emmènerai & téléphoner & téléproner & je télépronais & je télépronerai \\
\hline mettre & je mettais & je mettrai & tourner & tourrer & je tourrais & je tourrerai \\
\hline partager & je partageais & je partagerai & excuser & excuper & je excupais & j'excuperai \\
\hline compter & je comptais & je compterai & visiter & tisiter & je tisitais & je tisiterai \\
\hline traîner & je trainais & je trainerai & enlever & ennever & j'ennevais & j'ennèverai \\
\hline connaître & je connaissais & je connaîtrai & chercher & cherther & je cherthais & je chertherai \\
\hline retrouver & je retrouvais & je retrouverai & suivre & duivre & je duivais & je duivrai \\
\hline dîner & je dînais & je dînerai & envoyer & envorer & j'envorais & j'envorai \\
\hline joindre & je joignais & je joindrai & marcher & varcher & je varchais & je vacherai \\
\hline reposer & je reposais & je reposerai & vivre & divre & je divais & je divrai \\
\hline ouvrir & j'ouvrais & j'ouvrirai & rester & mester & je mestais & je mesterai \\
\hline toucher & je touchais & je toucherai & calmer & cilmer & je cilmais & je cilmerai \\
\hline revoir & je revoyais & je reverrai & contrôler & convrôler & je convrôlais & je convrôlerai \\
\hline essayer & j'essayais & essaierai & refaire & redaire & je redaisais & je rederai \\
\hline promener & je promenais & je promènerai & tomber & vomber & je vombais & je vomberai \\
\hline partir & je partais & je partirai & acheter & acreter & j'acretais & j'acrèterai \\
\hline reprendre & je reprenais & je reprendrai & écrire & écrare & j'écravais & j'écrarai \\
\hline devoir & je devais & je devrai & annoncer & innoncer & j'innonçais & j'innoncerai \\
\hline appeler & j'appelais & j'appellerai & boire & roire & je ruvais & je roirai \\
\hline apprendre & j'apprenais & j'apprendrai & montrer & gontrer & je gontrais & je gontrerai \\
\hline ramener & je ramenais & je ramènerai & écouter & élouter & j'éloutais & j'élouterai \\
\hline répéter & je répétais & je répéterai & recevoir & jecevoir & je jecevais & je jecevrai \\
\hline comprendre & je comprenais & je comprendrai & réussir & raussir & je raussissais & je raussirai \\
\hline vérifier & je vérifiais & je vérifierai & décider & décuder & je décudais & je décuderai \\
\hline changer & je changeais & je changerai & raconter & ragonter & je ragontais & je ragonterai \\
\hline arriver & j'arrivais & j'arriverai & danser & danter & je dantais & je danterai \\
\hline libérer & je libérais & je libérerai & vendre & lendre & je lendais & je lendrai \\
\hline
\end{tabular}




\begin{tabular}{|c|c|c|c|c|c|c|}
\hline Base-word & Past tense & Future tense & Base-Word & Pseudowords & Past tense & Future tense \\
\hline remplacer & je remplaçais & je remplacerai & poser & toser & je tosais & je toserai \\
\hline éviter & j'évitais & j'éviterai & retirer & retider & je retidais & je retiderai \\
\hline sentir & je sentais & je sentirai & nettoyer & pettoyer & je pettoyais & je pettoierai \\
\hline rêver & je rêvais & je rêverai & réveiller & réteiller & je réteillais & je réteillerai \\
\hline nourrir & je nourrissais & je nourrirai & laver & faver & je favais & je faverai \\
\hline devenir & je devenais & je deviendrai & commencer & combencer & je combençais & je combencerai \\
\hline réfléchir & je réfléchissais & je réfléchirai & amener & avener & je avenais & j'avènerai \\
\hline croire & je croyais & je croirai & vouloir & voumoir & je voumais & je voumrai \\
\hline manger & je mangeais & je mangerai & amuser & ameser & je amesais & j'ameserai \\
\hline offrir & j'offrais & j'offrirai & traverser & traperser & je trapersais & je traverserai \\
\hline expliquer & j'expliquais & j'expliquerai & rejoindre & renoindre & je renoignais & je renoindrai \\
\hline respirer & je respirais & je respirerai & descendre & descenvre & je descenvais & je descenvrai \\
\hline prévenir & je prévoyais & je préviendrai & atteindre & atreindre & je atreignais & j'atreindrai \\
\hline manquer & je manquais & je manquerai & aider & aiper & j'aipais & j'aiperai \\
\hline finir & je finissais & je finirai & lever & pever & je pevais & je pèverai \\
\hline imaginer & j'imaginais & j'imaginerai & présenter & prépenter & je prépentais & je prépentai \\
\hline installer & j'installais & j'installerai & regarder & remarder & je remardais & je remarderai \\
\hline porter & je portais & je porterai & retourner & revourner & je revournais & je revournerai \\
\hline sortir & je sortais & je sortirai & continuer & contipuer & je contipuais & je contipuai \\
\hline entendre & j'entendais & j'entendrai & mener & meper & je mepais & je mèperai \\
\hline conduire & je conduisais & je conduirai & supporter & bupporter & je bupportais & je bupporterai \\
\hline dormir & je dormais & je dormirai & occuper & occuver & j'occuvais & je occuverai \\
\hline régler & je réglais & je réglerai & attendre & atteudre & j'atteudais & j'atteudrai \\
\hline livrer & je livrais & je livrerai & oublier & dublier & je dubliais & je dublirai \\
\hline échapper & j'échappais & j'échapperai & garder & varder & je vardais & je varderai \\
\hline récupérer & je récupérais & je récupérerai & inviter & insiter & j'insitais & j'insiterai \\
\hline choisir & je choisissais & je choisirai & convaincre & conlaincre & je conlainquais & je conlaincrai \\
\hline arrêter & j'arrêtais & j'arrêterai & attraper & attrader & j'attradais & j'attraderai \\
\hline venir & je venais & je viendrai & utiliser & ugiliser & j'ugillisais & j'ugiliserai \\
\hline pouvoir & je pouvais & je pourrai & étudier & émudier & j'émudiais & j'émudierai \\
\hline prouver & je prouvais & je prouverai & construire & conspruire & je conspruisais & je conspruirai \\
\hline
\end{tabular}




\begin{tabular}{|c|c|c|c|c|c|c|}
\hline Base-word & Past tense & Future tense & Base-Word & Pseudowords & Past tense & Future tense \\
\hline fermer & je fermais & je fermerai & traiter & troiter & je troitais & je troiterai \\
\hline accepter & j'acceptais & j'accepterai & avancer & apancer & j'apançais & j'apancerai \\
\hline trouver & je trouvais & je trouverai & jouer & pouer & je pouais & je pouerai \\
\hline préparer & je préparais & je préparerai & rentrer & reutrer & je reutrais & je reutrerai \\
\hline découvrir & je découvrais & je découvrirai & répondre & pépondre & je pépondais & je pépondrai \\
\hline servir & je servais & je servirai & obtenir & ontenir & j'ontenais & j'ontiendrai \\
\hline donner & je donnais & je donnerai & discuter & discurer & je discurais & je discurai \\
\hline surveiller & je surveillais & je surveillerai & apporter & apporrer & j'apporrais & j'apporrerai \\
\hline monter & je montais & je monterai & couper & rouper & je roupais & je rouperai \\
\hline rencontrer & je rencontrais & je rencontrerai & casser & gasser & je gassais & je gasserai \\
\hline tenir & je tenais & je tiendrai & virer & varer & je varais & je varerai \\
\hline réparer & je réparais & je réparerai & embrasser & embrasper & j'embraspais & je embrasperai \\
\hline remettre & je remettais & je remettrai & défendre & dégendre & je dégendais & je dégendrai \\
\hline créer & je créais & je créerai & rater & jater & je jatais & je jaterai \\
\hline revenir & je revenais & je reviendrai & rendre & mendre & je mendais & je mendrai \\
\hline entrer & j' entrais & j'entrerai & taire & vaire & je vaisais & je vaisai \\
\hline séparer & je séparais & je séparerai & remercier & redercier & je rederciais & je redercierai \\
\hline soigner & je soignais & je soignerai & accompagner & accomsagner & j'accomsagnais & j'accomsagnerai \\
\hline rappeler & je rappelais & je rappellerai & arranger & adranger & j'adrangeais & j'adrangerai \\
\hline
\end{tabular}




\section{Figure 1.}

Schematic description of the basic design for yes-responses (words).

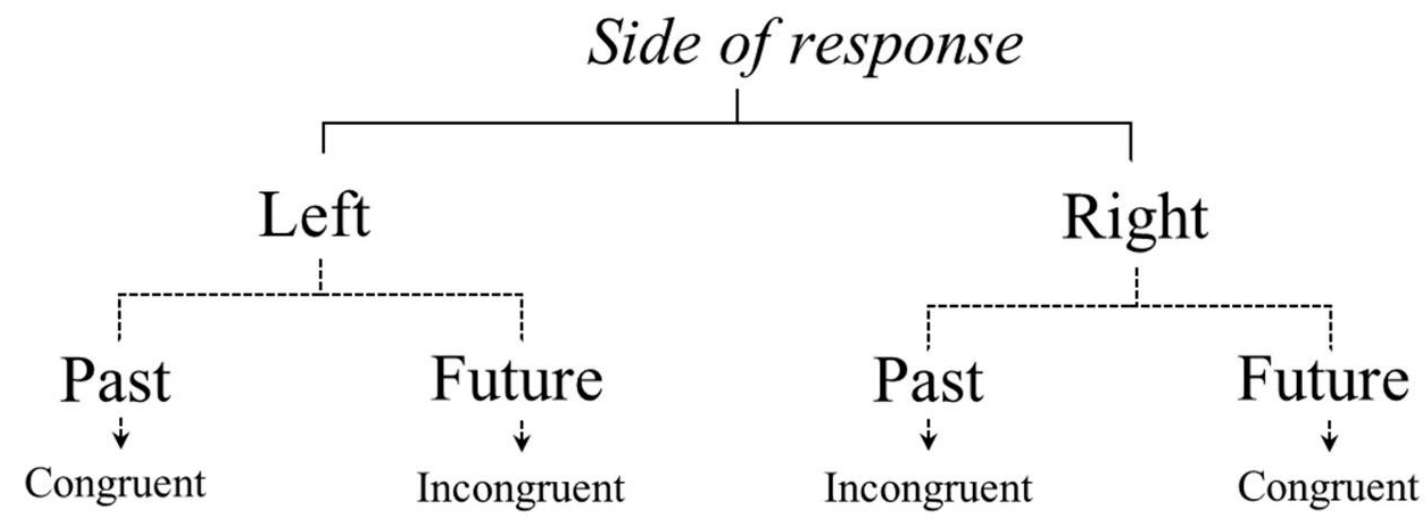

Note. Past-tense words that require a left-side response and future-tense words that require a right-side response are congruent with the mental timeline. When the same words require responses on the opposite side, they become incongruent (i.e., past to the right and future to the left). 
Figure 2.

Task design of Experiment 1.

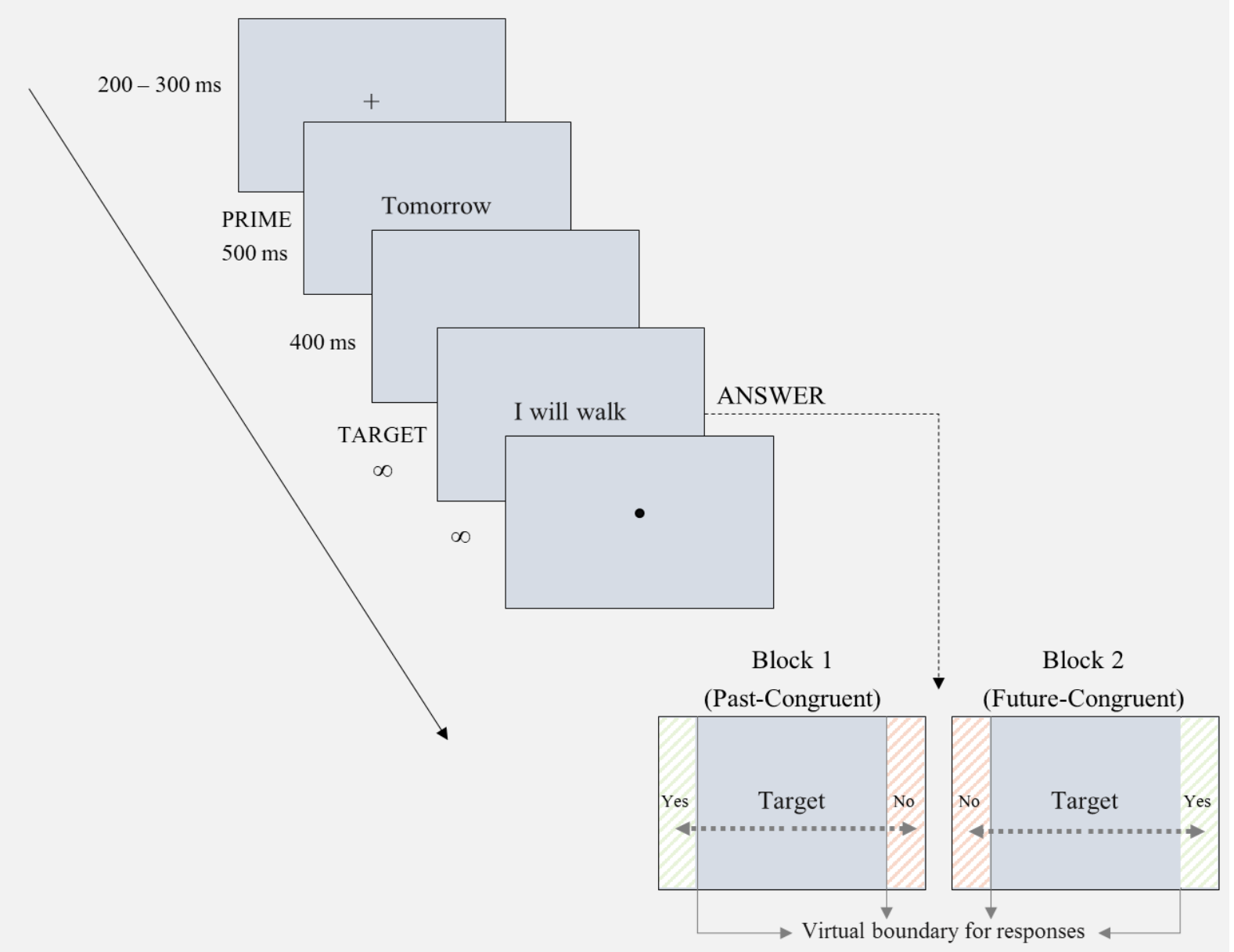

Note. After the fixation cross, a prime ("yesterday" or "tomorrow") was displayed, followed by a real target word or pseudoword. Participants made their lexical decision after the onset of the target by moving their pen on the trackpad towards the left or right. To start a new trial, participants had to replace the pen at the center of the trackpad (indicated by a black dot). Target words and pseudowords remained on the screen until a response was made. 
Figure 3.

Experiment 1. Mean reaction times (A) and mean error rates (B) as a function of response side (left vs. right) and verb tense (past vs. future).
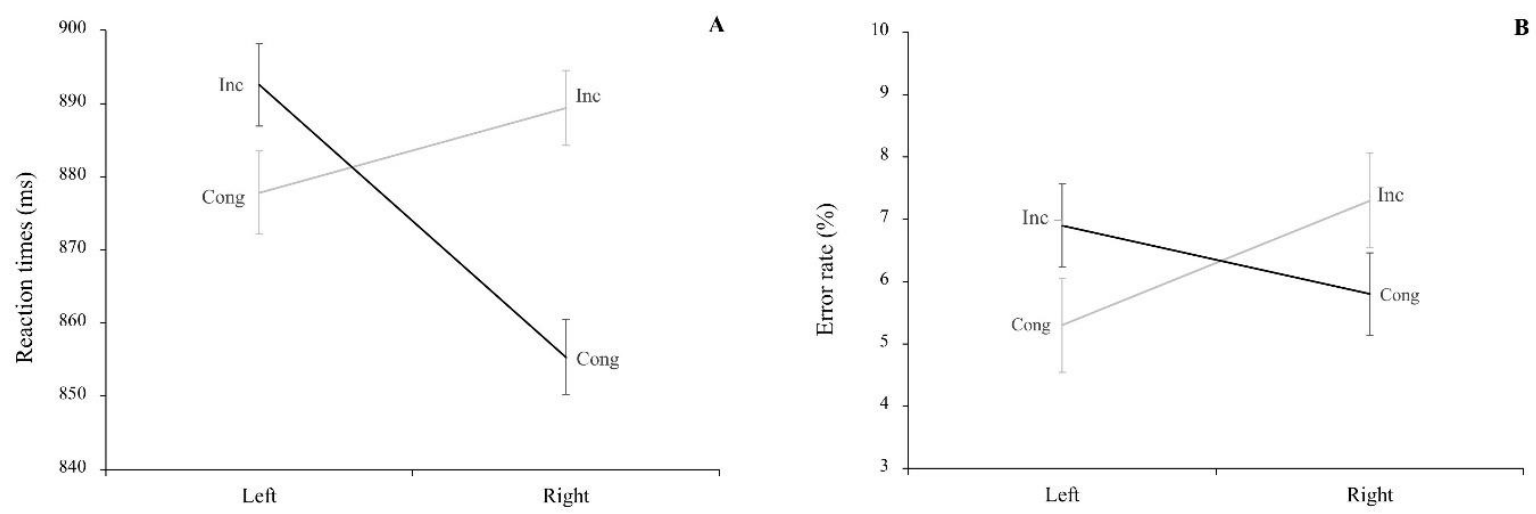

Past _ Future

Note. Inc: Incongruent, Cong: Congruent. Mean errors were normalized for tense for the graphical representation of the congruency effect. Error bars indicate within-participant standard errors. 


\section{Figure 4.}

Experiment 2. Mean reaction times and mean error rates as a function of response side (left vs. right), verb tense (past vs. future), and movement (trackpad vs. mouse vs. keyboard).
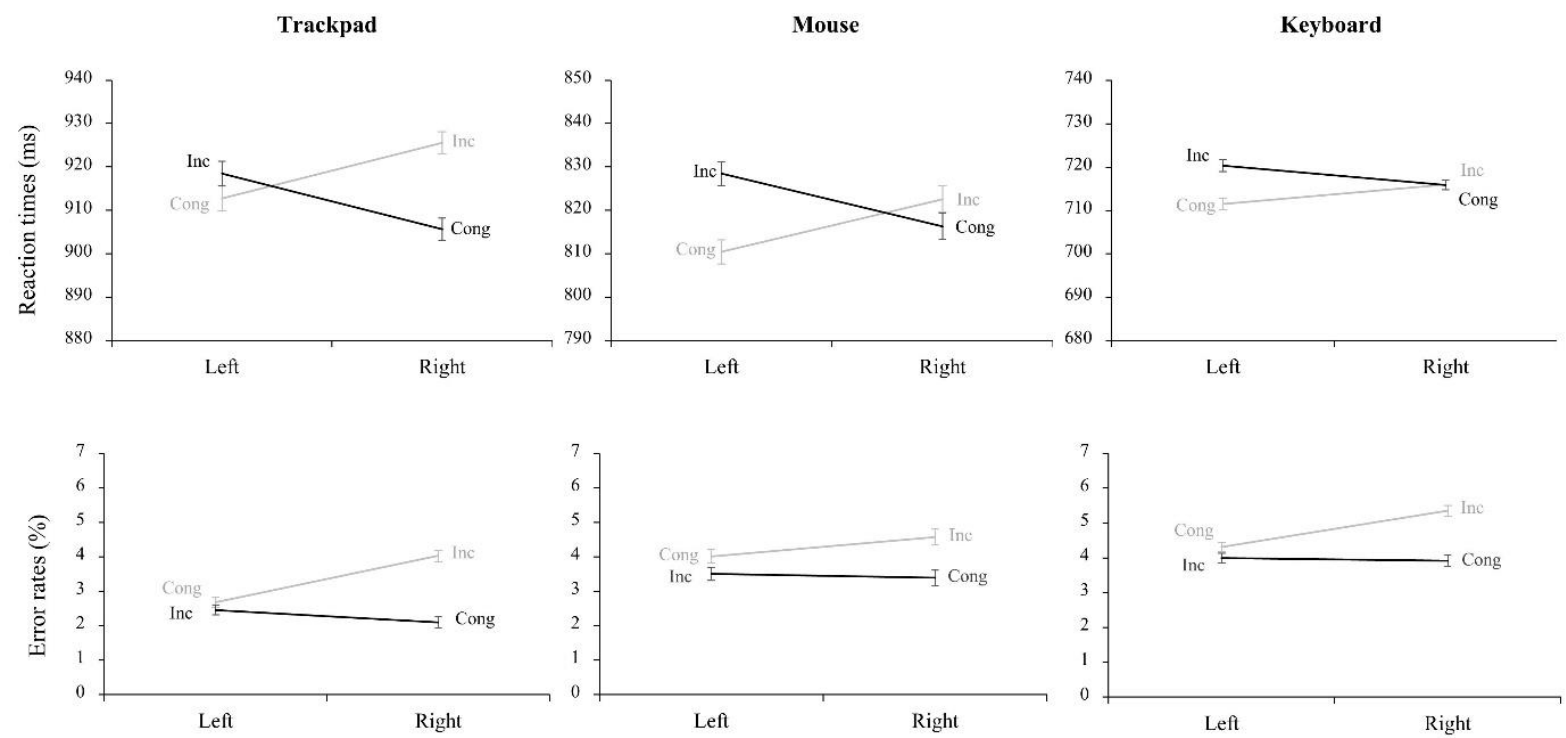

_ Past — Future

Note. Because the group of participants who responded to the right was globally faster than the group that responded to the left, we normalized the RTs for side. Note that this normalization only affects the visual presentation of the results but not the statistical significance of the congruency effect. Error bars indicate within-participant standard errors. 


\section{Figure 5.}

Experiment 3. Mean reaction times (A) and mean error rates (B) as a function of response side (left vs. right) and verb tense (past vs. future).
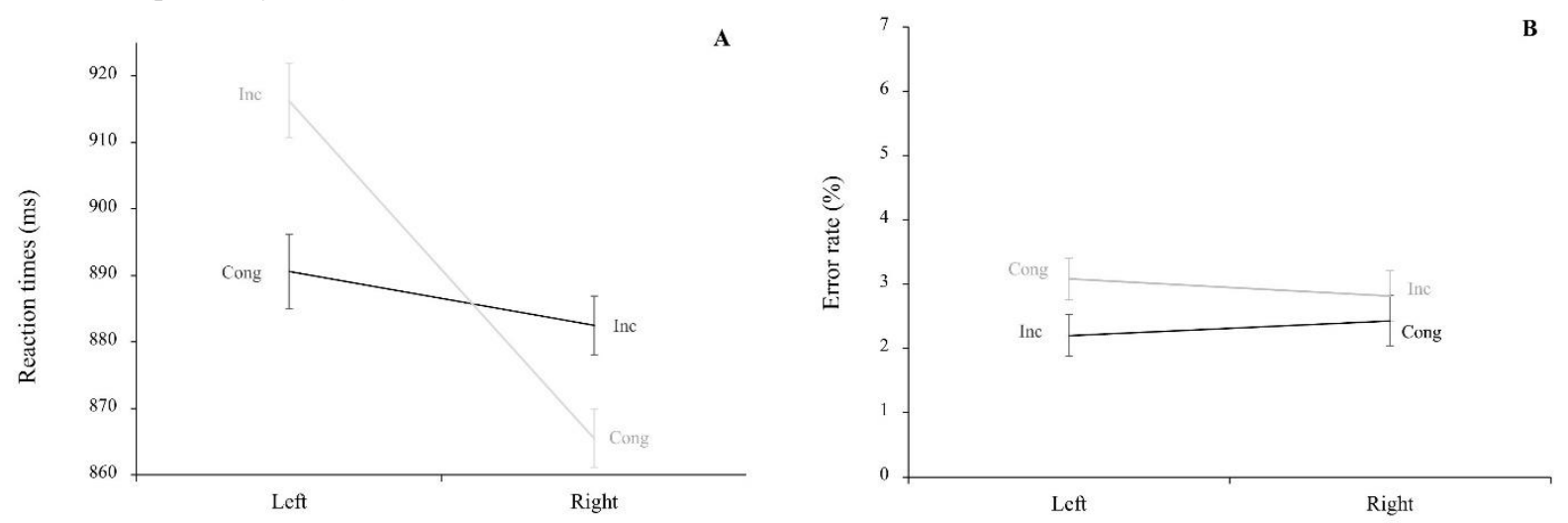

Note. Inc: Incongruent, Cong: Congruent. Error bars indicate within-participant standard errors. 
Figure 6.

Summary of the adjusted mean effect sizes (Cohen's d) and corresponding forest plot for our own experiments (upper panel) and the results of the meta-analysis by von Sobbe et al. (2019) (lower panel).

\begin{tabular}{|c|c|c|c|c|c|c|c|}
\hline \multirow[b]{2}{*}{ Movement } & \multirow[b]{2}{*}{ Cohen's d } & \multicolumn{6}{|c|}{ Statictics for each study } \\
\hline & & SE & Var & $\begin{array}{c}\text { CI Lower } \\
\text { limit }\end{array}$ & $\begin{array}{c}\text { CI Upper } \\
\text { limit }\end{array}$ & Z-Value & p-Value \\
\hline EXPE 1 (Trackpad) & 0.744 & 0.235 & 0.055 & 0.314 & 1,234 & 3.297 & 0.001 \\
\hline EXPE 2 (Trackpad) & 0.386 & 0.083 & 0.007 & 0.223 & 0.550 & 4.643 & 0.000 \\
\hline EXPE 2 (Mousc) & 0.437 & 0.099 & 0.010 & 0.243 & 0.632 & 4.407 & 0.000 \\
\hline EXPE 3 (Trackpad) & 0.648 & 0.209 & 0.044 & 0.238 & 1.059 & 3.097 & 0.002 \\
\hline Summary & 0.450 & 0.059 & 0.003 & 0.334 & 0.566 & 7.618 & 0.000 \\
\hline No movement & Cohen's d & SE & Var & $\begin{array}{l}\text { CI Lower } \\
\text { limit }\end{array}$ & $\begin{array}{c}\text { CI Upper } \\
\text { limit }\end{array}$ & Z-Value & p-Value \\
\hline EXPE 2 (Kcyboard) & 0.152 & 0.089 & 0.008 & -0.023 & 0.327 & 1.701 & 0.089 \\
\hline \multicolumn{8}{|l|}{ Von Sobbe et al, (2019) } \\
\hline & Cohen's d & SE & Var & $\begin{array}{l}\text { CI Lower } \\
\text { limit }\end{array}$ & $\begin{array}{l}\text { CI Upper } \\
\text { limit }\end{array}$ & Z-Value & $\mathrm{p}$-Value \\
\hline Time is task relcyant & 0.463 & 0.038 & 0.001 & 0.390 & 0.537 & 12.346 & 0.000 \\
\hline Time is task irrelevant & 0.087 & 0.047 & 0.002 & -0.005 & 0.179 & 1.853 & 0.064 \\
\hline Temporal priming & 0.465 & 0.485 & 0.007 & 0.298 & 0.633 & 5.411 & 0.000 \\
\hline Summary & 0.338 & 0.028 & 0.001 & 0.278 & 0.386 & 11.984 & 0.000 \\
\hline
\end{tabular}
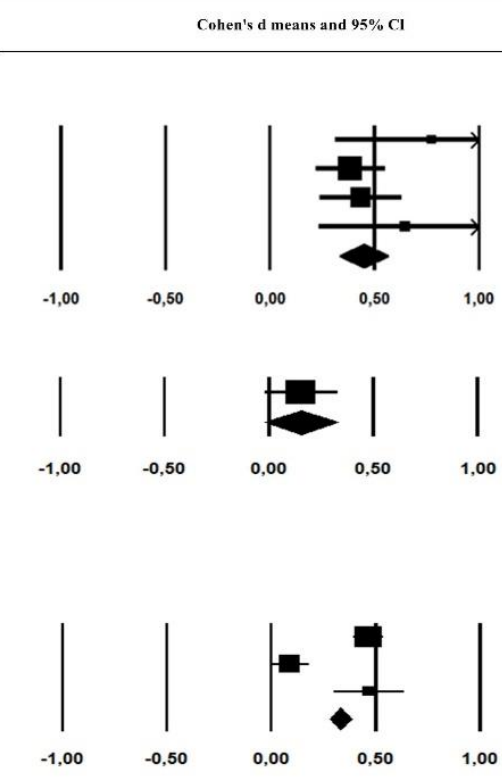

Note. SE: standard error. Var: variance. CI: confidence interval. 